\title{
CHARACTERIZATION OF GENETIC DIVERSITY AND RELATIONSHIP IN ALMOND (PRUNUS DULCIS [MILL.] D.A. WEBB.) GENOTYPES BY RAPD AND ISSR MARKERS IN SULAIMANI GOVERNORATE
}

\author{
MAHOOD, A. M. R. ${ }^{*}$ - HAMA-SALIH, F. M. \\ Horticulture Department, College of Agricultural engineering Sciences, University of Sulaimani \\ Sulaimani-Kurdistan Region, Iraq \\ *Corresponding author \\ e-mail: anwar.rauf@univsul.edu.iq; phone:+96-4770-1532-547
}

(Received $13^{\text {th }}$ Oct 2019; accepted $21^{\text {st }}$ Jan 2020)

\begin{abstract}
Genetic diversity of 38 almond local genotypes was investigated using RADP and ISSR markers with the analysis of nut morphology. Samples were taken from five locations for this study, including Sharbazher, Mergapan, Qaradakh, Barznja, and Hawraman. Almond nuts width, length and thickness were studied and their mean values were observed to range between 16.18-27.21 mm, 24.18-41.07 $\mathrm{mm}$ and 11.49-16.81 mm, respectively. Polymorphic bands of mean values were 9.5 for random amplified polymorphic DNA (RAPD) and 8 for inter-simple sequence repeat (ISSR). The PIC values were recorded for RAPD primes to range between 0.77 to 0.97 and those for ISSR primers were also verified between 0.36 to 0.97 . Based on Jaccard similarity coefficients, the genetic distances were recorded between 0.32 (B-G3 vs. B-G4) (M-G2 vs. M-G1) to 0.75 (H-G5 vs. Q-G1) and all genotypes were grouped into 3 major clusters (A, B and C) with a mean dissimilarity 0.535 for 20 RADP markers. In the case of the 15 ISSR markers, a genetic distance between 0.19 (H-G13 vs. H-G12) to 0.78 (H-G5 vs. B-G6) was also observed, with four clades (A, B, C and D) with a mean dissimilarity of 0.485. According to STRUCTURE analysis, all genotypes were divided into two groups. Analysis of molecular variance (AMOVA) demonstrated a high-level genetic differentiation within a population $88 \%$ for RAPD and $87 \%$ for ISSR.
\end{abstract}

Keywords: morphological traits, genetic relationship, genetic structure, random amplified polymorphic DNA, inter-simple sequence repeat

\section{Introduction}

Almond (Prunus dulcis (Mill.)) D.A. Webb syn. P. amygdalus L. Batsch is a commercially important fruit plant, from the Rosaceae family (Zhu, 2014; Sakar et al., 2019). The place of wild almond is originated at the arid mountainous region of Central Asia and deserts of western China, Iran, Turkistan, Afghanistan, Kurdistan, and Southwest Asia with subsequent expansion into European and North African regions (Browicz and Zohary, 1996; Kester and Gradziel, 1996; Xu et al., 2004) and it is also grown commercially around the world. Global almond production for 2018/19 is an estimated 1.4 million metric tons (USDA, 2018). Botanists observed over 30 species, subspecies with ecotype (Grasselly, 1976; Ladizinsky, 1999). Genetically, Almond is diploid, the chromosome number is $2 \mathrm{n}=2 \mathrm{x}=16$ with a genome size approximately 246 Mb (Sánchez-Pérez et al., 2019).

Almond is one of the vital plants that can grow under the rain-fed condition in Iraq, particularly in the Kurdistan region. Therefore, it is important to know the adaptation of this tree that able to tolerate the biotic and abiotic stresses. Almond is a large-sized tree, with long generation time and also has a low level of variability in morphology traits (Casas et al., 1999; Sorkheh et al., 2007, 2009; Zeinalabedini et al., 2008; Bouhadida et al., 2009). To provide information about genetic relationships it is important to study the 
differences at the level of agronomic, morphological and biochemical traits (Khan et al., 2016). Genetic diversity is an important tool that breeders can use to detect and identify with differentiation all genotypes and also it is a useful tool to improve the chances of the selection of better segregates for various characters (Dwevedi and Lal, 2009). Using morphological traits to the identification of almond plants is restricted, because of their environmental variations. However, morphological traits, including seed length and kernel size normally can be used.

In Kurdistan, Iraq, information about almond genotypes has been poorly recognized. Therefore, the modern molecular genetic tool can be applied to identify and characterize the relationships among them. However, several similar studies have been performed regarding genetically recognized cultivars and wild species of almond.

Molecular markers have shown the vital role in crop breeding, particularly in genetic diversity research and gene bank. PCR-based DNA marker systems are generally used, including Random amplified polymorphic DNA (RAPD), inter-simple sequence repeat (ISSR), amplified fragment length polymorphism (AFLP) and more recently simple sequence repeats (SSRs) or microsatellites (Gupta et al., 2000).

Since no molecular evidence was obtainable concerning the almond genotypes grown in Sulaimani region, therefore, the consciousness and conception of the genetic diversity in Sulaimani almond accessions are important for the implementation of degree addressed to their usages and preservations. The present study was aimed to estimate the genetic diversity with relatedness among the most important almond genotypes and for the first time their population structure in Sulaimani was developed for almond genotypes by using RAPD and ISSR markers.

\section{Materials and Methods}

\section{Locations and plant material}

Five locations (Fig. 1, Table 1) were selected for this study with thirty-eight almond local genotype trees distributed, including Sharbazher (9), Mergapan (3), Qaradakh (5), Barznja (7), and Hawraman (14).

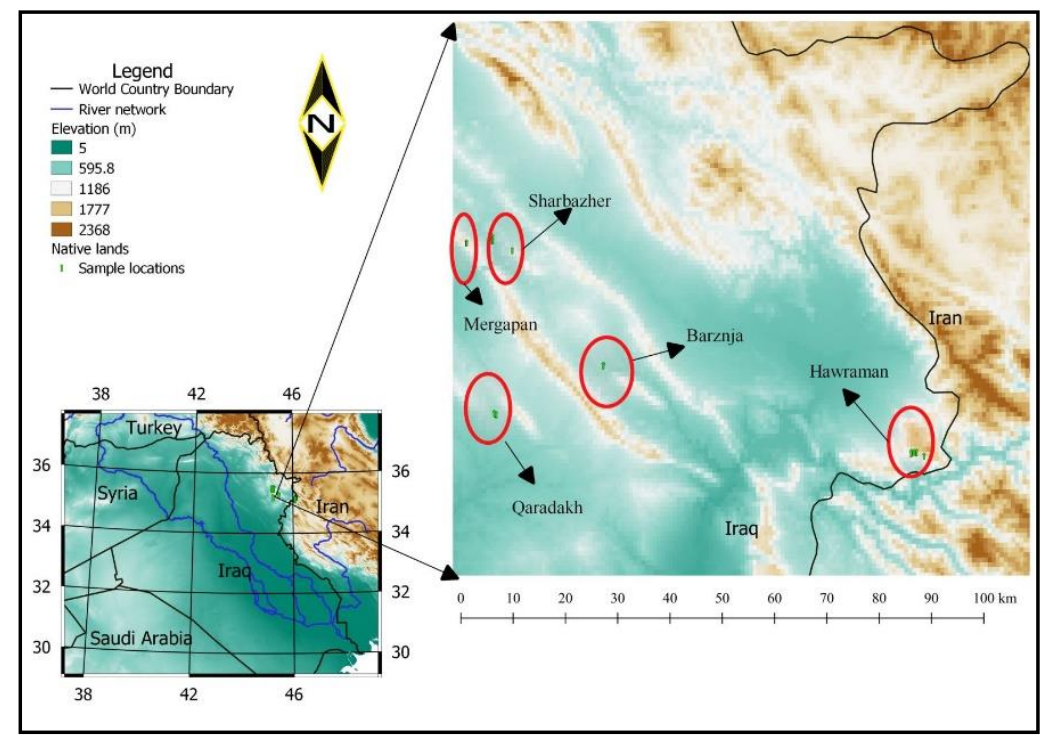

Figure 1. Distribution of collection sites of study plant materials in Sulaimani governorate 


$$
-1741-
$$

Table 1. Genotypes name, location, latitude and altitude

\begin{tabular}{|c|c|c|c|c|}
\hline \multirow{2}{*}{ Genotypes name } & \multirow{2}{*}{ Locations } & \multicolumn{2}{|c|}{ Latitude } & \multirow{2}{*}{ Altitude } \\
\hline & & $\mathbf{N}^{\circ}$ & $\mathbf{W}^{\circ}$ & \\
\hline SH-G1 to SH-G9 & Sharbazher & $35^{\circ} 49^{\prime} 30^{\prime \prime}$ & $45^{\circ} 18^{\prime} 93^{\prime \prime}$ & 997.6 \\
\hline M-G1 to M-G3 & Mergapan & $35^{\circ} 48^{\prime} 93^{\prime \prime}$ & $45^{\circ} 13^{\prime} 47^{\prime \prime}$ & 1148 \\
\hline Q-G1 to Q-G5 & Qaradagh & $35^{\circ} 19^{\prime} 29^{\prime \prime}$ & $45^{\circ} 19^{\prime} 69^{\prime \prime}$ & 925.8 \\
\hline B-G1 to B-G7 & Barznja & $35^{\circ} 27^{\prime} 69^{\prime \prime}$ & $45^{\circ} 42^{\prime} 21^{\prime \prime}$ & 1154 \\
\hline H-G1 to H-G14 & Hawraman & $35^{\circ} 12^{\prime} 38^{\prime \prime}$ & $46^{\circ} 07^{\prime} 80^{\prime \prime}$ & 1402 \\
\hline
\end{tabular}

\section{Morphological study of seeds}

Almond nuts were collected from each genotype (Fig. 2) Impurities such as damaged or broken nut, dust and dirt have been eliminated. For each nut, weight and size dimensions (the three axial dimensions) including length, width, and thickness of the nuts were measured by using a digital calliper with an accuracy of $0.01 \mathrm{~mm}$. The nuts were cracked, then using a hammer and kernel weighted to calculate shelling percentage.

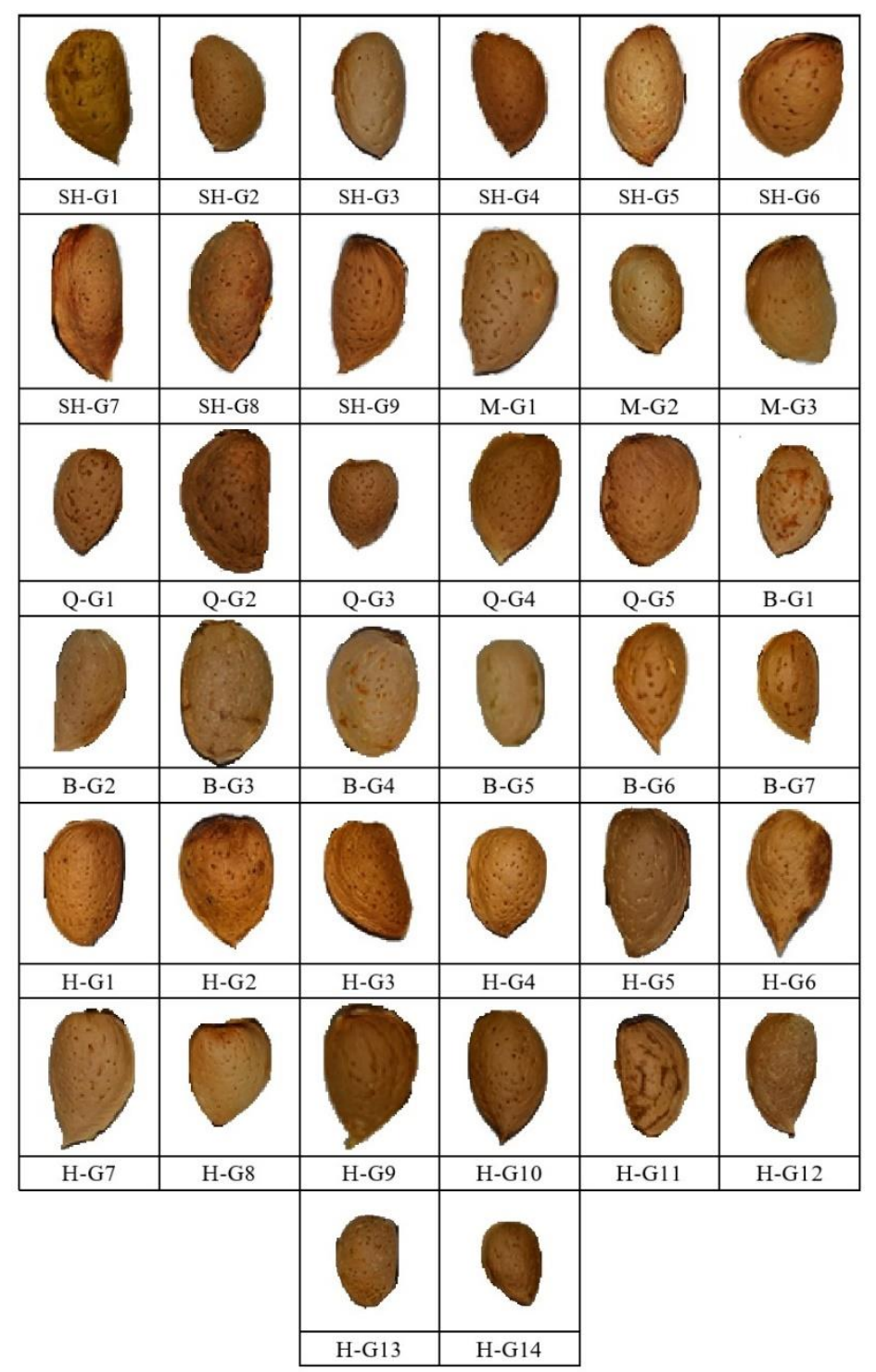

Figure 2. Shows the different morphological shapes of all almond genotypes nut, (Scale 1:1.75) 


\section{Genomic DNA extraction and purification}

The CTAB DNA extraction protocol with some modifications was used to isolate genomic DNA, according to (Tahir and Hama Karim, 2011). Briefly, 1 gram of fresh leaves was ground and frozen in liquid nitrogen and then $2 \mathrm{ml}$ of CTAB buffer was added and incubated at $60^{\circ} \mathrm{C}$ for $60 \mathrm{~min}$. (1 M Tris $\mathrm{HCl}(\mathrm{pH} 8.0), 5 \mathrm{M} \mathrm{NaCl}, 0.5 \mathrm{M}$ EDTA and $2 \mathrm{~g}$ of CTAB (cetyltrimethyl ammonium bromide)), the DNA sample was precipitated with 0.08 volumes of ammonium acetate and 0.54 volumes of ice isopropanol, and then the DNA pellet was washed with $1 \mathrm{ml}$ of ice-cold $70 \%$ ethanol and then the dried pellet was resuspended in 50-100 $\mu 1$ of deionized water. DNA was treated with RNase to remove RNA contamination. The DNA concentration was analyzed by electrophoresis using a $1.5 \%$ agarose gel.

\section{RAPD analysis}

Twenty primers were utilized in this work, (Table 2$)$. The reaction mixture $(20 \mu 1)$ was prepared for 1 volume sample $(1 \mathrm{x})$ which is $10 \mu \mathrm{l}$ of master mix buffer with $(0.7 \mu \mathrm{l})$ primer $(20 \mathrm{pmol} / \mu \mathrm{l}), 4 \mu \mathrm{l}$ genomic DNA $(100 \mathrm{ng} / \mu \mathrm{l})$ and then the total volume was completed up to $20 \mu \mathrm{l}$ by distilled water. Amplification was carried out in a thermo-cycler (Master cycler) for 36 cycles, each consisting of an initial denaturation step at $94^{\circ} \mathrm{C}$ for 10 minutes, denaturation at $94^{\circ} \mathrm{C}$ for 1 minute, annealing temperature at at $36^{\circ} \mathrm{C}$ for 1 minute with extension step at $72^{\circ} \mathrm{C}$ for 2 minutes and then final synthesis step of 10 minutes at $72^{\circ} \mathrm{C}$, Amplification products were separated on $1.5 \%$ agarose gel in $1 \mathrm{X}$ TAE (Tris base, acetic acid and EDTA) buffer. Gels were run at a constant voltage of $100 \mathrm{~V}$ for 60 minutes, then imaged using a UV trans-illuminator. The image was captured by a digital imaging system.

\section{ISSR analysis}

Fifteen primers were utilized in this study, (Table 2$)$. The reaction mixture $(20 \mu \mathrm{l})$ was prepared for one volume sample (1x) which is $10 \mu \mathrm{l}$ of master mix buffer with $0.7 \mu \mathrm{l}$ primer $20 \mathrm{pmol} / \mu \mathrm{l}, 4 \mu \mathrm{l}$ genomic DNA $(100 \mathrm{ng} / \mu \mathrm{l})$ and then the total volume was completed up to $20 \mu \mathrm{l}$ by distilled water. Amplification was carried out in a thermo-cycler (Master cycler) for 36 cycles, each consisting of an initial denaturation step at $94^{\circ} \mathrm{C}$ for ten minutes, denaturation at $94^{\circ} \mathrm{C}$ for 1 minute, annealing temperature at $50^{\circ} \mathrm{C}$ for 1 minute with extension step at $72^{\circ} \mathrm{C}$ for 2 minutes and then final synthesis step of 10 minutes at $72^{\circ} \mathrm{C}$, Amplification products were separated on $1.5 \%$ agarose gel in $1 \mathrm{X}$ TAE (Tris base, acetic acid and EDTA) buffer.

\section{Design primers}

Primers were designed regarding many papers including (Martins et al., 2003; Sharma et al., 2012; Pinar et al., 2015; Abodoma et al., 2017; Saleh et al., 2018).

\section{Statistical analysis data and counting}

ANOVA and comparison test among genotypes were performed by XLSTAT software. The scorable bands were coded manually as either present (1) or absent (0) (Tahir et al., 2019) and morphological data were converted to matrix data to create the PCA plot and dendrogram using Euclidean distance and Jaccard methods. 
Table 2. Primer names, sequences and annealing temperature of RAPD and ISSR markers used in this study

\begin{tabular}{|c|c|c|c|c|}
\hline $\begin{array}{c}\text { Primer } \\
\text { Number }\end{array}$ & Primer Name & $\begin{array}{l}\text { Primer Sequences } \\
\mathbf{5} \longrightarrow 3\end{array}$ & $\begin{array}{c}\text { Annealing } \\
\text { Temperature } \\
\left({ }^{\circ} \mathbf{C}\right) \\
\end{array}$ & $\begin{array}{l}\text { Molecular Weight of } \\
\text { Bands (pb) }\end{array}$ \\
\hline \multicolumn{5}{|c|}{ RAPD } \\
\hline 1 & OPA-08 & GTGACGTAGG & 36 & $250-1500$ \\
\hline 2 & OPA-10 & GTGATCGCAG & 36 & $500-2000$ \\
\hline 3 & OPA-11 & CAATCGCCGT & 36 & $500-2000$ \\
\hline 4 & OPA-16 & AGCCAGCGAA & 36 & $500-1750$ \\
\hline 5 & OPB-11 & GTAGACCCGT & 36 & $260-2200$ \\
\hline 6 & S075 & ACGGATCCTG & 36 & $240-2500$ \\
\hline 7 & S084 & CAGACAAGCC & 36 & $270-2100$ \\
\hline 8 & S085 & CTCTGTTCGG & 36 & $350-2600$ \\
\hline 9 & S081 & TCGCCAGCCA & 36 & $250-1750$ \\
\hline 10 & S093 & CCACCGCCAG & 36 & $360-1600$ \\
\hline 11 & S078 & GGCTGCAGAA & 36 & $250-2100$ \\
\hline 12 & S094 & AGAGATGCCC & 36 & $260-1550$ \\
\hline 13 & S087 & GGTGCAGTCG & 36 & $270-1600$ \\
\hline 14 & S088 & GGTCCTCAGG & 36 & $250-2500$ \\
\hline 15 & S089 & CAGTTCGAGG & 36 & $260-1900$ \\
\hline 16 & S090 & TACCGACACC & 36 & $265-1850$ \\
\hline 17 & S091 & TCGGAGTGGC & 36 & $260-1950$ \\
\hline 18 & S092 & ACTCAGGAGC & 36 & $350-2100$ \\
\hline 19 & S095 & CAGTTCTGGC & 36 & $1750-380$ \\
\hline 20 & S073 & CCAGATGCAC & 36 & $340-1900$ \\
\hline \multicolumn{5}{|c|}{ ISSR } \\
\hline 1 & 807 & AGAGAGAGAGAGAGAGT & 50 & $400-1000$ \\
\hline 2 & 17898A & CACACACACACAAC & 55 & $260-2200$ \\
\hline 3 & HB04 & GACAGACAGACAGACA & 60 & $260-1500$ \\
\hline 4 & HB 8 & GAGAGAGAGAGAGG & 50 & $270-1700$ \\
\hline 5 & HB10 & GAGAGAGAGAGACC & 50 & $300-1700$ \\
\hline 6 & HB11 & GTGTGTGTGTGTCC & 50 & $370-1650$ \\
\hline 7 & HB12 & CACCACCACGC & 50 & $275-1850$ \\
\hline 8 & HB15 & GTGGTGGTGGC & 50 & $250-1850$ \\
\hline 9 & AG7YC & AGAGAGAGAGAGAGYC & 55 & $450-1400$ \\
\hline 10 & AGC6G & AGCAGCAGCAGCAGCAGCG & 55 & $260-1450$ \\
\hline 11 & IS06 & GTGCGTGCGTGCGTGC & 60 & $380-1100$ \\
\hline 12 & IS16 & DHBCGACGACGACGACGA & 60 & $280-1500$ \\
\hline 13 & IS17 & BDBACAACAACAACAACA & 57 & $300-1700$ \\
\hline 14 & IS19 & YHYGTGTGTGTGTG & 57 & $270-1600$ \\
\hline 15 & ISSR.08 & ACACACACACACACACYA & 52 & $250-2000$ \\
\hline
\end{tabular}

\section{Results and Discussion}

\section{Morphological data analysis}

Agro-morphological important traits in almond genotypes are nut phenotypic parameters including width, length, thickness, weight, shelling percentage for the economic and health sector. Therefore, identification of morphological traits can be discussed alongside with genetic diversity. To improve the gene pool, the physical traits are inappropriate because environmental factors have a direct influence on developmental stages of the plant with all traits consequently, they demonstrate the diversity among genotypes are just limited (Terzopoulos and Bebeli, 2008). (Table 3) shows the mean values of width, length, thickness, weight and shell to the kernel of nuts from thirty-eight almond genotypes, statistical differences were observed. Nut width of the almond genotypes ranged between 16.18 to $27.21 \mathrm{~mm}$, length from 24.18 to 41.07 $\mathrm{mm}$, thickness between 11.49 to $16.81 \mathrm{~mm}$, nut weight from 2.13 to $7.52 \mathrm{~g}$ and shell to kernel percentage between 16.39 to $30.84 \%$. It can be seen that our results nearly agree with Esfahlan 


$$
-1744 \text { - }
$$

et al., 2012. The values of some almond nut parameters in 40 almond genotypes statistically varied. Nut weight ranged between 3.23 to $8.34 \mathrm{~g}$, nut length from 30.5 to $43.6 \mathrm{~mm}$, nut width from 18.3 to $29.4 \mathrm{~mm}$, and nut thickness 15.00 to $22.33 \mathrm{~mm}$. Kodad et al. (2014) recorded that physical nut traits in 45 almonds with Moroccan genotypes the minimum and maximum nut width were 15.90-27.19 mm, nut length 19.25 to $41.24 \mathrm{~mm}$, nut thickness $11.48-19.61 \mathrm{~mm}$, nut weight 1.15-7.34 $\mathrm{g}$ and shelling percentage 19.91-63.79\%. In addition, differences in agronomical nut data might be due to the insentience characteristics of genotypes (Kumar and Ahmed, 2015). Furthermore, geographical locations with cross-pollination by insects could be another evidence of almond diversity. (Kester and Gradziel, 1996; Woolley et al., 2000).

Table 3. Effect of almond tree genotypes on some nut characteristics

\begin{tabular}{|c|c|c|c|c|c|c|c|c|c|c|}
\hline \multirow{2}{*}{$\begin{array}{c}\text { Genotype } \\
\text { SH-G1 }\end{array}$} & \multicolumn{2}{|c|}{$\begin{array}{c}\text { Nut Width } \\
(\mathrm{mm})\end{array}$} & \multicolumn{2}{|c|}{$\begin{array}{c}\text { Nut Length } \\
\text { (mm) }\end{array}$} & \multicolumn{2}{|c|}{$\begin{array}{c}\text { Nut Thickness } \\
\text { (mm) }\end{array}$} & \multicolumn{2}{|c|}{$\begin{array}{c}\text { Nut Weight } \\
(\mathrm{g})\end{array}$} & \multicolumn{2}{|c|}{$\begin{array}{c}\text { Shell to Kernel } \\
(\%)\end{array}$} \\
\hline & 23.41 & c-e & 38.62 & a-d & 14.88 & $c-g$ & 4.94 & c-e & 19.09 & $\mathrm{j}-\mathrm{m}$ \\
\hline SH-G2 & 20.18 & h-l & 33.35 & $f-m$ & 14.81 & $c-g$ & 4.03 & e-1 & 17.93 & $1-n$ \\
\hline SH-G3 & 19.20 & j-o & 32.13 & $j-n$ & 13.87 & e-1 & 4.61 & $c-h$ & 21.33 & $e-j$ \\
\hline SH-G4 & 20.61 & h-k & 34.42 & e-1 & 15.03 & $c-g$ & 4.98 & $c-e$ & 19.80 & h-1 \\
\hline SH-G5 & 20.79 & $g-j$ & 36.82 & $b-f$ & 15.22 & b-e & 4.60 & $c-h$ & 21.21 & $f-j$ \\
\hline SH-G6 & 20.78 & $g-j$ & 36.58 & $c-g$ & 15.61 & $a-d$ & 4.08 & e-1 & 22.08 & $e-h$ \\
\hline SH-G7 & 20.39 & h-k & 39.65 & $a-c$ & 14.37 & $c-j$ & 5.00 & $c-e$ & 22.56 & $d-f$ \\
\hline SH-G8 & 22.52 & d-g & 38.54 & $a-d$ & 15.70 & $a-c$ & 4.25 & $e-k$ & 21.90 & $e-i$ \\
\hline SH-G9 & 17.64 & $n-q$ & 36.40 & $c-h$ & 12.98 & $k-n$ & 3.75 & h-m & 24.57 & $\mathrm{~cd}$ \\
\hline M-G1 & 22.76 & $d-f$ & 40.39 & $a b$ & 14.62 & $c-i$ & 4.91 & $c-f$ & 16.39 & $\mathrm{n}$ \\
\hline M-G2 & 21.92 & $e-h$ & 32.86 & g-n & 15.06 & $c-g$ & 4.35 & $c-j$ & 16.49 & $\mathrm{n}$ \\
\hline M-G3 & 23.63 & c-e & 40.55 & $\mathrm{ab}$ & 14.82 & $\mathrm{c}-\mathrm{g}$ & 6.31 & $\mathrm{~b}$ & 16.97 & $\mathrm{mn}$ \\
\hline Q-G1 & 21.22 & $f-i$ & 30.74 & $1-n$ & 14.95 & $c-g$ & 4.46 & $c-i$ & 19.68 & h-1 \\
\hline Q-G2 & 26.65 & $\mathrm{a}$ & 41.07 & $\mathrm{a}$ & 14.60 & $c-i$ & 4.79 & $c-g$ & 29.14 & $a b$ \\
\hline Q-G3 & 20.91 & $g-j$ & 25.75 & o & 16.37 & $a b$ & 3.72 & $h-m$ & 27.74 & $\mathrm{~b}$ \\
\hline Q-G4 & 25.97 & $a b$ & 35.52 & d-k & 16.81 & $\mathrm{a}$ & 7.52 & $\mathrm{a}$ & 16.41 & $\mathrm{n}$ \\
\hline Q-G5 & 27.21 & $\mathrm{a}$ & 35.68 & $d-j$ & 14.57 & $c-i$ & 6.40 & $\mathrm{~b}$ & 17.08 & $\mathrm{mn}$ \\
\hline B-G1 & 19.34 & $j-n$ & 29.73 & $\mathrm{mn}$ & 12.66 & $1-0$ & 2.40 & op & 20.71 & $f-j$ \\
\hline B-G2 & 19.15 & j-o & 31.78 & k-n & 12.28 & $\mathrm{~m}-\mathrm{o}$ & 3.44 & $j-n$ & 25.29 & $\mathrm{c}$ \\
\hline B-G3 & 24.56 & $\mathrm{bc}$ & 38.05 & a-e & 14.61 & $c-i$ & 5.24 & $\mathrm{~cd}$ & 18.22 & $k-n$ \\
\hline B-G4 & 24.04 & $\mathrm{~cd}$ & 32.62 & h-n & 14.67 & $c-h$ & 4.48 & $c-i$ & 20.36 & $\mathrm{f}-\mathrm{k}$ \\
\hline B-G5 & 17.49 & $o-q$ & 28.97 & $\mathrm{n}$ & 12.91 & k-n & 3.50 & $i-n$ & 20.36 & $\mathrm{f}-\mathrm{k}$ \\
\hline B-G6 & 16.54 & $\mathrm{pq}$ & 32.44 & $i-n$ & 11.87 & no & 2.13 & $\mathrm{p}$ & 19.80 & h-1 \\
\hline B-G7 & 16.18 & $\mathrm{q}$ & 30.23 & $\mathrm{mn}$ & 13.38 & h-m & 2.17 & $\mathrm{p}$ & 30.84 & $\mathrm{a}$ \\
\hline H-G1 & 19.11 & j-o & 31.54 & $1-n$ & 12.99 & k-n & 3.82 & g-1 & 23.58 & $c-e$ \\
\hline $\mathrm{H}-\mathrm{G} 2$ & 22.78 & $d-f$ & 33.02 & $g-m$ & 15.30 & b-d & 2.80 & $m-p$ & 20.57 & $\mathrm{f}-\mathrm{k}$ \\
\hline H-G3 & 18.18 & $m-p$ & 31.55 & $1-n$ & 11.49 & o & 3.44 & $j-n$ & 19.63 & i-1 \\
\hline H-G4 & 22.84 & $c-f$ & 29.80 & $\mathrm{mn}$ & 15.13 & $b-f$ & 2.73 & $\mathrm{n}-\mathrm{p}$ & 21.29 & $e-j$ \\
\hline H-G5 & 22.55 & d-g & 37.19 & $b-e$ & 13.16 & $j-n$ & 5.31 & $\mathrm{c}$ & 19.16 & $j-m$ \\
\hline H-G6 & 19.78 & i-m & 36.21 & $c-i$ & 13.27 & $i-m$ & 3.91 & $\mathrm{f}-1$ & 22.56 & $d-f$ \\
\hline H-G7 & 24.28 & $\mathrm{~cd}$ & 36.20 & $c-i$ & 14.22 & d-k & 4.30 & $\mathrm{~d}-\mathrm{k}$ & 22.00 & $e-i$ \\
\hline H-G8 & 22.96 & $c-f$ & 30.42 & $\mathrm{mn}$ & 12.92 & $k-n$ & 4.07 & e-1 & 19.44 & $j-1$ \\
\hline H-G9 & 21.50 & $f-i$ & 39.10 & $a-d$ & 13.77 & $\mathrm{f}-1$ & 4.06 & e-1 & 20.77 & $f-j$ \\
\hline H-G10 & 20.72 & h-k & 32.67 & h-n & 14.82 & $\mathrm{c}-\mathrm{g}$ & 4.01 & e-1 & 20.41 & $\mathrm{f}-\mathrm{k}$ \\
\hline H-G11 & 18.56 & $1-0$ & 31.59 & $1-n$ & 13.44 & h-m & 3.42 & $j-n$ & 25.67 & $\mathrm{c}$ \\
\hline H-G12 & 17.74 & $n-q$ & 31.80 & k-n & 13.07 & $j-n$ & 3.32 & $\mathrm{k}-\mathrm{O}$ & 20.16 & g-1 \\
\hline H-G13 & 18.96 & $\mathrm{k}-\mathrm{o}$ & 24.88 & $\mathrm{o}$ & 13.74 & g-1 & 3.13 & $1-0$ & 24.76 & $\mathrm{c}$ \\
\hline H-G14 & 16.81 & $\mathrm{pq}$ & 24.18 & o & 12.24 & $\mathrm{~m}-\mathrm{o}$ & 2.48 & op & 22.45 & d-g \\
\hline
\end{tabular}

Different letters in the same column indicate significant differences between means according to Duncan multiple range test at $\mathrm{P} \leq 0.05$. 
The principal component analyses (PCA) plot (Fig. 3) showed the distribution of all genotypes and morphological data on the plot. The plot demonstrated a negative relationship between shell to the kernel and nut weight. It displayed also, a positive linkage between nut width and nut thickness.

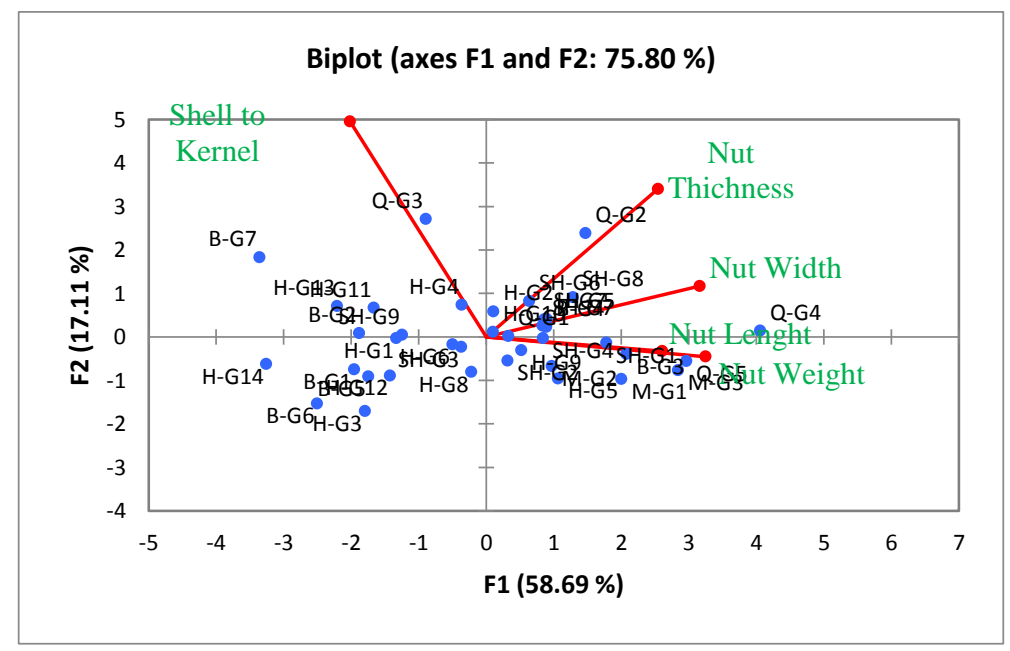

Figure 3. PCA plot among 38 genotype accessions based on 5 nut characteristics in different locations

\section{Allelic variation in almond accessions using RAPD and ISSR markers}

RAPD and ISSR markers were used to analyze the genetic diversity of almond genotypes. The assessment of genetic diversity and relationships among almond specimens has been more important to improve the chances of better selection segregates for various characters (Pinar et al., 2015). The valuation of genetic diversity is significant not only for plant development but also for efficient management and conservation of germplasm resources. Information about genetic relationships is important to represent the differences at the DNA level and molecular characteristics about all genotypes. It is also significant for the breeding program which detects drought-resistant traits which is a vital trait to improve economically important crops (Khan et al., 2016). In our results of the primers tested, 20 (out of 21) RAPD and 15 (out of 17) ISSR primers were confirmed as amplified fragments for their reproducibility and high polymorphism (Table 4). The maximum, minimum and mean values of polymorphic bands were 5, 15 and 9.5 for RAPD and 4, 12 and 8 for ISSR, respectively. The PIC values were recorded for RAPD primes that ranged between 0.77 to 0.97 and for ISSR primers it was also verified between 0.35 to 0.96 . The PIC values discovered are nearly similar to those reported such as The PIC values for 16 RAPD primers exhibited by Sharma et al. (2012) ranging from 0.26 to 0.87. Mean value of PIC was reported 0.77 using 80 primers of RAPD to 29 almond cultivars (Sorkheh et al., 2009). Shiran et al., (2007) demonstrated that the PIC values were confirmed as ranged 0.47 to 0.97 using 42 RAPD randomly primer to apply 39 almond varieties. In addition, for ISSR markers, range of PIC was got from (0.59 to 0.69) by using 21 primers that applied to 29 prunus species (Sarhan et al., 2015). In another research 9 ISSR primers were used in the peach plant, PIC ranged between 0.71 to 0.88 was documented (Tian et al., 2015). Furthermore, PIC values ranging from 0.13 to 0.47 and 0.12 to 0.47 were verified after using (37 RAPD and 38 ISSR) random primers for 


$$
-1746-
$$

45 peach cultivars respectively (Sharma and Sharma, 2018). Regarding the polymorphic bands, El Hawary et al. (2014) demonstrated 2.8 mean value of the polymeric band for 10 primers, and also mean of the polymorphic band was recorded as 8.36 (Gouta et al., 2008). Abodoma et al. (2017) also reported that the polymorphic band for using nine ISSR primer was 13.2 and mean value of polymeric band was 5.53 using 13 primers (Cabrita et al., 2014) recorded polymorphic band was 4.23 for 13 RAPD primer (Pinar et al., 2015) but 5 was got for 4 ISSR primers. Moreover, the average allele polymorphism was 18.6 per primer using ISSR primers applied to 29 prunus species (Sarhan et al., 2015).

Table 4. Markers name, number of polymorphic bands, major allele frequency, gene diversity and PIC value of 20 RAPD and 15 ISSR

\begin{tabular}{|c|c|c|c|c|}
\hline Marker & $\begin{array}{c}\text { Number of polymorphic } \\
\text { bands }\end{array}$ & Major Allele Frequency & Gene Diversity & PIC \\
\hline \multicolumn{5}{|c|}{ 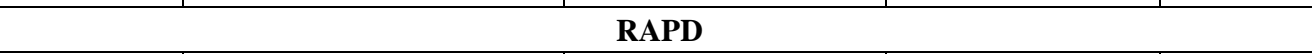 } \\
\hline OPA-08 & 5 & 0.18 & 0.89 & 0.88 \\
\hline OPA-10 & 11 & 0.13 & 0.96 & 0.96 \\
\hline OPA-11 & 11 & 0.05 & 0.97 & 0.97 \\
\hline OPA-16 & 7 & 0.13 & 0.94 & 0.94 \\
\hline OPB-11 & 12 & 0.21 & 0.92 & 0.92 \\
\hline S075 & 15 & 0.08 & 0.96 & 0.96 \\
\hline S084 & 10 & 0.13 & 0.94 & 0.94 \\
\hline S085 & 12 & 0.24 & 0.92 & 0.92 \\
\hline S081 & 8 & 0.32 & 0.87 & 0.86 \\
\hline S093 & 11 & 0.45 & 0.78 & 0.77 \\
\hline S078 & 12 & 0.21 & 0.91 & 0.91 \\
\hline S094 & 9 & 0.08 & 0.96 & 0.96 \\
\hline S087 & 8 & 0.24 & 0.87 & 0.86 \\
\hline S088 & 10 & 0.16 & 0.95 & 0.95 \\
\hline S089 & 8 & 0.08 & 0.96 & 0.95 \\
\hline S090 & 7 & 0.13 & 0.93 & 0.93 \\
\hline S091 & 7 & 0.24 & 0.89 & 0.88 \\
\hline S092 & 9 & 0.16 & 0.93 & 0.93 \\
\hline S095 & 10 & 0.16 & 0.93 & 0.93 \\
\hline S073 & 8 & 0.16 & 0.93 & 0.92 \\
\hline Mean & 9.5 & 0.18 & 0.92 & 0.92 \\
\hline \multicolumn{5}{|c|}{ ISSR } \\
\hline 807 & 7 & 0.63 & 0.59 & 0.58 \\
\hline $17898 \mathrm{~A}$ & 11 & 0.08 & 0.96 & 0.96 \\
\hline HB04 & 10 & 0.13 & 0.94 & 0.93 \\
\hline HB8 & 7 & 0.08 & 0.96 & 0.96 \\
\hline HB10 & 4 & 0.53 & 0.66 & 0.62 \\
\hline HB11 & 7 & 0.13 & 0.92 & 0.91 \\
\hline HB12 & 12 & 0.18 & 0.92 & 0.91 \\
\hline HB15 & 4 & 0.79 & 0.37 & 0.35 \\
\hline AG7YC & 11 & 0.08 & 0.97 & 0.96 \\
\hline AGC6G & 8 & 0.11 & 0.95 & 0.94 \\
\hline IS06 & 10 & 0.08 & 0.96 & 0.96 \\
\hline IS16 & 6 & 0.50 & 0.69 & 0.66 \\
\hline IS17 & 5 & 0.50 & 0.71 & 0.69 \\
\hline IS19 & 9 & 0.16 & 0.92 & 0.91 \\
\hline ISSR.08 & 9 & 0.34 & 0.86 & 0.85 \\
\hline Mean & 8 & 0.29 & 0.82 & 0.81 \\
\hline
\end{tabular}




\section{Clustering and AMOVA analysis}

Clustering analyses were performed for assessing the connection between Almond genotypes, based on the Jaccard similarity coefficients using the unweighted pair-group method (UPGMA). The dissimilarity coefficients were ranged between 0.32 (B-G3 vs. B-G4) (M-G2 vs. M-G1) to 0.75 (H-G5 vs. Q-G1), all 38 Almond genotypes were clustered into 3 groups (A, B and C) with a mean dissimilarity (0.54) for 20 RADP markers (Fig. 4), cluster A include H-G3, SH-G3, SH-G6, H-G4, H-G8, SH-G7, H-G11, H-G5, H-G9, H-G12, H-G7, H-G6, H-G2 and H-G10, only Q-G1 was observed in cluster $\mathrm{B}$, the rest of the genotypes were found in cluster $\mathrm{C}$. In addition, dissimilarity values were also observed between 0.19 (H-G13 vs. H-G12) to 0.78 (H-G5 vs. B-G6) by using 15 ISSR markers which clustered all genotypes into A, B, C and D with a mean dissimilarity of 0.49 (Fig. 5). Cluster A includes only $\mathrm{H}-\mathrm{G} 7$, and group B is consent of all genotypes without cluster A, C, D) group C involves H-G1, SH-G6 and SH-G7, H-G3, H-G5, H-G4, H-G6 and H-G14 belong to cluster D. In addition, both RADP and ISSR markers, exhibited a dissimilarity between 0.32 (B-G3 vs. B-G4) to 0.72 (H-G1 vs. H-G9) and clustered all genotypes into 4 groups (A, B, C and D) with a mean dissimilarity of 0.52 (Fig. 6). Cluster A, include H-G7, group B involves H-G4, H-G6, H-G8, H-G5, H-G11, $\mathrm{H}-\mathrm{G} 10, \mathrm{H}-\mathrm{G} 12, \mathrm{H}-\mathrm{G} 13, \mathrm{H}-\mathrm{G} 2$ and $\mathrm{H}-\mathrm{G} 9$, cluster $\mathrm{C}$ includes all genotypes that are not in cluster A, B, and D and cluster D includes H-G14, H-G3, SH-G3, SH-G6 and SH-G7. Many researchers registered regarding Almond genetic diversity and their relationships. Martins et al. (2003) studied the genetic diversity of Portuguese Prunus dulcis cultivars and their relationship using (RAPD) and (ISSR) markers, the UPGMA dendrogram also achieved a good degree of confidence between associations which was a cophenetic correlation higher than 0.80 for 124 amplified fragments. In addition, four main clusters included P. dulcis cultivars (cluster I); P5 (cluster II); P. webbii (cluster III); and $P$. persica (cluster IV), the outgroup. Pinar et al. (2015) demonstrated that dissimilarity coefficients were 0.90 and clusters and sub-clusters of the dendrogram had values of cophenetic correlation higher than 0.85 between genotypes by using the UPGMA method for the total number of amplified RAPD plus ISSR fragments with a dendrogram consisting of nine main clusters.

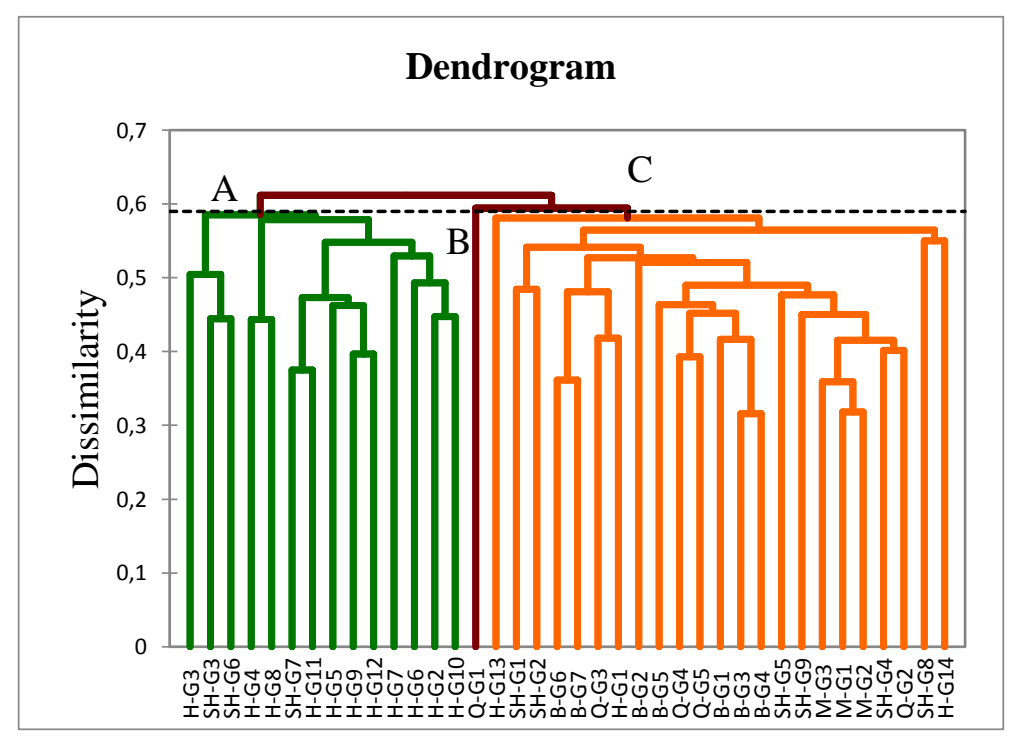

Figure 4. Cluster tree created by UPGMA method based on 20 RAPD markers among 38 almond genotypes 


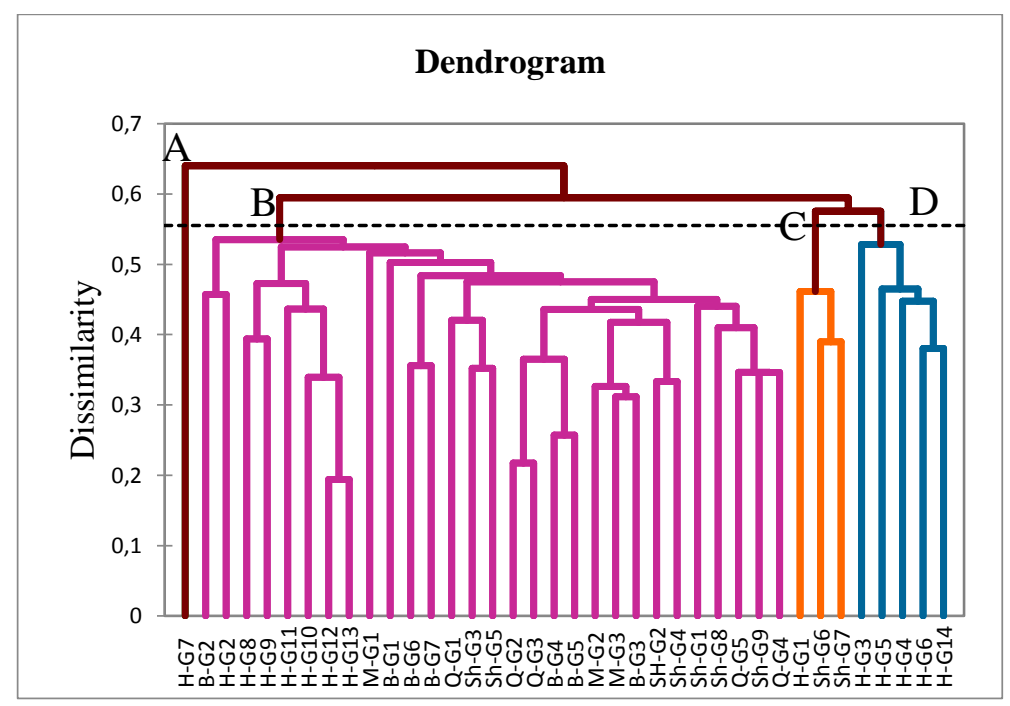

Figure 5. Cluster tree created by UPGMA method based on 15 ISSR markers among 38 almond genotypes

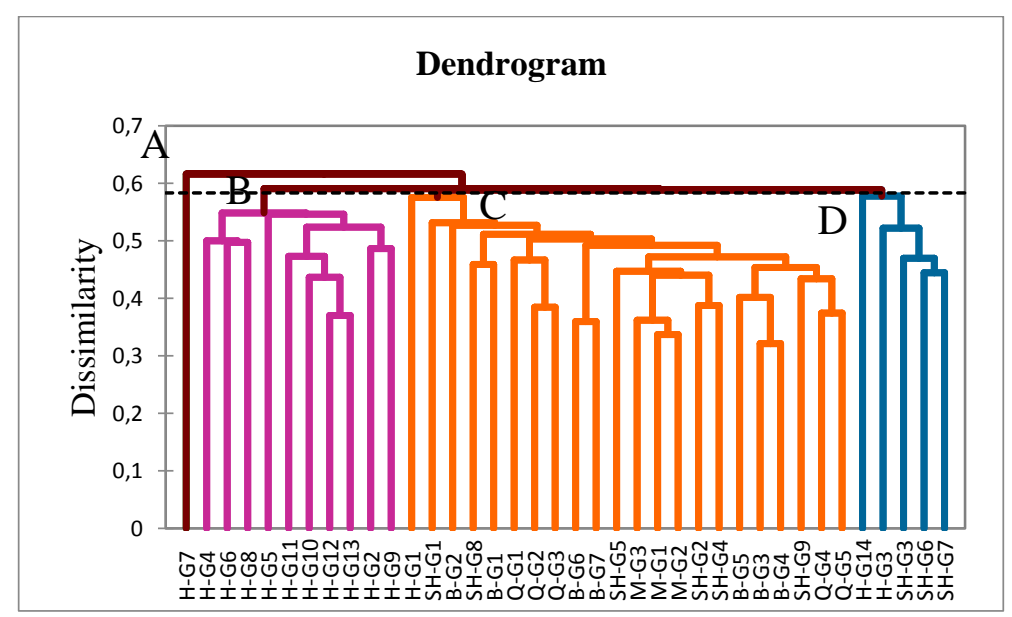

Figure 6. Cluster tree created by UPGMA method based on 20 RAPD with 15 ISSR markers among 38 almond genotypes

The genetic variety among the 86 almond cultivars and genotypes were assessed using 15 SSR marker and also UPGMA cluster analysis based on the similarity matrix coefficient was analyzed. Genetic similarities ranged from 0.03 (P. tenella and 'Ne Plus Ultra') to 1.00 (three accessions from Akdamar Island and Turkey) with an average of 0.29. Almond genotypes were clustered according to their pedigree and geographic origin. Based on the dendrogram of 86 almond cultivars genotypes, and wild species two groups of different size were formed, with $P$. tenella forming an outgroup and separated from the rest of the genotypes (Halász et al., 2019).

Analysis of molecular variance (AMOVA) of the 38 Almond genotypes in RAPD analysis demonstrated $88 \%$ of the total variation within the populations, and $12 \%$ was credited to differences between populations (Table 5). In addition, the ISSR marker revealed high variance in the intra-populations ( $87 \%$ of the total variation), and merely $13 \%$ could be qualified to differences between sub-populations. AMOVA analysis for 86 
genotypes using 15 SSR markers revealed that considerable genetic variation occurred within populations $(71.30 \%)$, and genetic variation among populations was $28.70 \%$ which is a significant reaching value (Halász et al., 2019). This level of variation among populations is much higher than the value estimated for $P$. sibirica (Wang et al., 2014) or P. mahaleb (Jordano and Godoy, 2000), and that shown by Fernández i Martí et al. (2015) in almond.

Table 5. Analysis of molecular variance (AMOVA) of the five populations for 38 Almond genotypes

\begin{tabular}{c|c|c|c|c|c|c}
\hline Source & df & SS & MS & Est. Var. & \% & P-Value \\
\hline \multicolumn{7}{c}{ RAPD } \\
\hline Among Pops & 4 & 307.18 & 76.80 & 5.29 & $12 \%$ & 0.001 \\
Within Pops & 33 & 1289.06 & 39.06 & 39.06 & $88 \%$ & 0.001 \\
Total & 37 & 1596.24 & & 44.35 & $100 \%$ & \\
\hline \multicolumn{7}{c}{ ISSR } \\
\hline Among Pops & 4 & 188.16 & 47.04 & 3.391 & $13 \%$ & 0.001 \\
Within Pops & 33 & 754.31 & 22.86 & 22.86 & $87 \%$ & 0.001 \\
Total & 37 & 942.47 & & 26.25 & $100 \%$ & \\
\hline
\end{tabular}

\section{Genetic structure for all genotypes using RAPD and ISSR markers}

STRUCTURE method was used to collect evidence about population structure for almond genotypes depending on allele frequencies (Evanno et al., 2005) therefore, in this work, according to Delta K, genotypes were divided into two groups or sub-populations, group 1 (green line) and group 2 (red line). For RAPD and ISSR (Fig. 7A and B) clusters were also represented by colour, the red line in RAPD and the green line in ISSR consisted of Hawraman location, but the green line in RAPD and the red line in ISSR conceited other locations including Sharbazher, Mergapan, Qaradakh and Barznja. In addition, a combination class of genotypes may refer to more than one background. For example, samples SH-G3 and Q-G1 in RAPD markers (Fig. 7A), and only sample Sh-G1 in ISSR marker (Fig. 7B) could possibly have a complicated history linking intercrossing or practicably resulting from the gene flow between taxa, in addition, the high variability between genotypes may be the consequences of the changing climates found within the locations. The true number of clusters $(\mathrm{K})$ in a sample of individuals was observed and determined for 20 RAPD and 15 ISSR markers, that the real highest $\mathrm{K}$ value was $\mathrm{K}=2$ for each marker (Fig. $7 C$ and D).

Allele frequencies using STRUCTURE analysis was investigated to determine the genetic constitution of different groups. The Evanno criterion gave a strong signal for $\mathrm{K}=9$ indicating nine genetically distinct subgroups resided within the studied genotypes (Halász et al., 2019). Our results are assessed depending on genetic diversity and relationships between different accessions in different locations of Sulaimani governorate, that had some morphological similarities within genotypes and molecular studies also have verified it. It can be said that this hypothesis may be conducted the selfincompatible nature of the almond plants. Janick (1990) demonstrated that the high heterosis of the cultivars is mostly due to cross-pollination among them and also it is recorded high genetic variability. In addition, growing almonds in different regions have also been isolated during the time period that has progressed of characteristic ecotypes. 


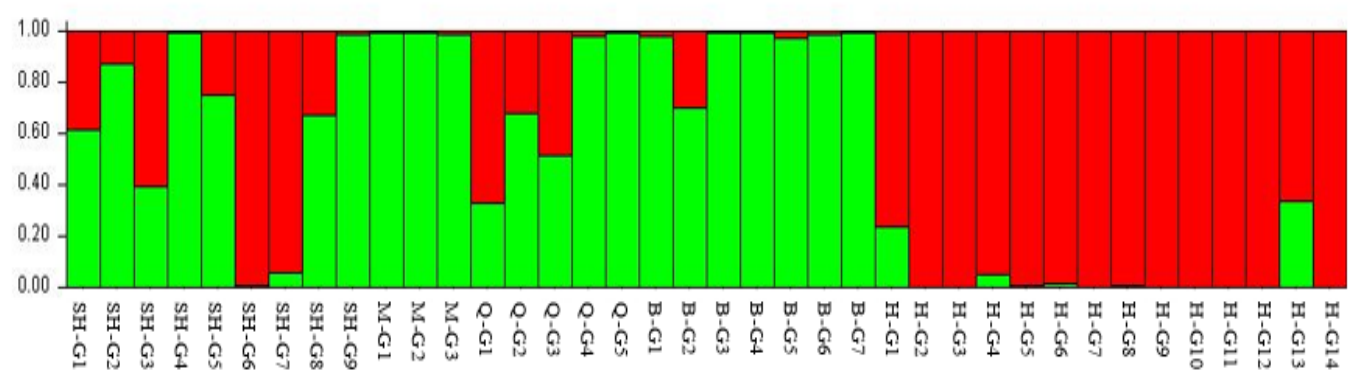

A

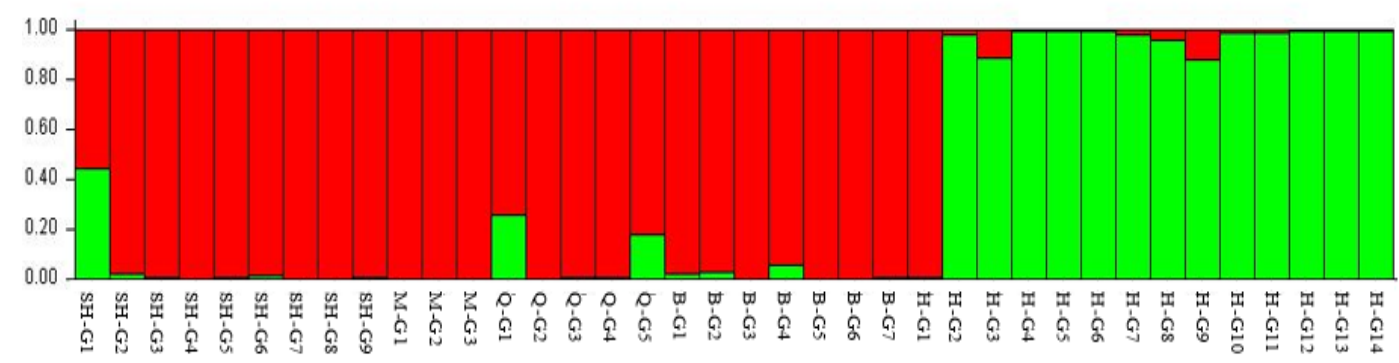

$\mathrm{B}$
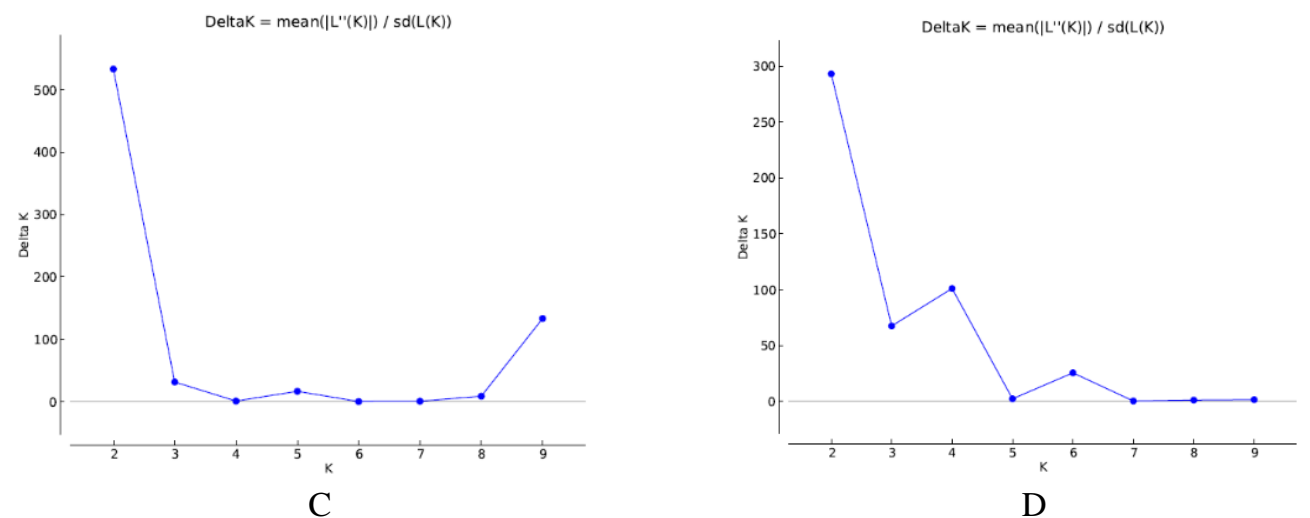

$\mathrm{D}$

Figure 7. Thirty-eight almond genotypes clustered into different sub-populations by STRUCTURE software. (A) for RAPD and (B) ISSR. Accessions are coordinated as per estimated membership coefficients $(q)$ in $K=2$ clusters. (C) for RAPD and (D) for ISSR,

Determining the optimal value of $K$ by the $(\Delta K)$ procedure described by Evanno et al., 2005

\section{Conclusions}

This work aimed to assess the genetic diversity using RAPD and ISSR mark with nut agronomical traits to 38 almond accessions grown in Sulaimani Iraq region. According to our research, Agronomical nuts (width, length, thickness, weight and shell to kernel data) were studied for each genotype that mean values of those parameters were significantly documented. Genetically, the number of polymorphic bands, major allele frequency, gene diversity and the polymorphism information content (PIC), were demonstrated. The polymorphic bands of mean value were 9.5 for RAPD and 8 for ISSR. The PIC values were recorded for RAPD primers ranging between (0.77 to 0.97$)$ and for ISSR primers it was also verified between 0.35 to 0.96 . Jaccard similarity coefficients were achieved between 0.32 (B-G3 vs. B-G4) (M-G2 vs. M-G1) to 0.75 (H-G5 vs. Q-G1) and clustered into 3 clusters (A, B and C) with a mean similarity of 0.54 for 20 RADP markers. For 15 
ISSR markers, 0.19 (H-G13 vs. H-G12) to 0.78 (H-G5 vs. B-G6) were also observed, and clustered into 4 clusters (A, B, C and D) with a mean similarity of 0.49 . In addition, based on the analysis of STRUCTURE software, RAPD and ISSR were analyzed and were divided into two groups, analysis of molecular variance stated a low variation among groups (12\%) for RAPD and (13\%) for ISSR. Therefore, the consequence of the genetic diversity in Sulaimani Almond accessions is important for breeding as well as to the implementation of degree addressed to their usages and preservations.

Our recommendations for future researches will be conducting quantitative traits loci analysis and genome-wide associated to determine QTL that associated with drought tolerance in almond genotypes, and also to assist future conservation and breeding programs to use different locations and accessions of almonds with using various types of markers including SNIPs, SRAPs, ALFPs, and SSRs.

Acknowledgements. We are grateful and thankful to Prof. Dr. Nawroz Abdula-razzak Tahir for his help with the software analysis and statistical analysis and also to Dr. Jamal Mahmood Faraj for his helpful comments and advice on an earlier draft of the manuscript.

\section{REFERENCES}

[1] Abodoma, A. F., Shehata, M. M., Elsherif, N. S., Amar, M. H., Khar, Kh. A. (2017): Biodiversity assessment for some almond genotypes cultivated in Libya using SRAP and ISSR. - Egyptian Journal of Genetics and Cytology 46(2): 13-41.

[2] Bouhadida, M., Casas, A. M., Gonzalo, M. J., Arús, P., Moreno, M. A., Gogorcena, Y. (2009): Molecular characterization and genetic diversity of Prunus rootstocks. - Scientia horticulturae 120(2): 237-245.

[3] Browicz, K., Zohary, D. (1996): The genus Amygdalus L. (Rosaceae): Species relationships, distribution and evolution under domestication. - Genetic Resources and Crop Evolution 43(3): 229-247.

[4] Cabrita, L., Apostolova, E., Neves, A., Marreiros, A., Leitão, J. (2014): Genetic diversity assessment of the almond (Prunus dulcis (Mill.) DA Webb) traditional germplasm of Algarve, Portugal, using molecular markers. - Plant Genetic Resources 12(S1): S164S167.

[5] Casas, A. M., Igartua, E., Balaguer, G., Moreno, M. A. (1999): Genetic diversity of Prunus rootstocks analyzed by RAPD markers. - Euphytica 110(2): 139-149.

[6] Dwevedi, K. K., Lal, G. M. (2009): Assessment of genetic diversity of cultivated chickpea (Cicer arietinum L.). - Asian Journal of Agricultural Sciences 1(1): 7-8.

[7] El Hawary, S. S., Sokkar, N. M., El Halawany, A. M., Kandil, Z. A., Tawab, S. A., Mokbel, H. A. (2014): Phytochemical screening, botanical study and DNA fingerprinting of Prunus amygdalus batsch "UMM alfahm" cultivar cultivated in Egypt. - International Journal of Pharmacy and Pharmaceutical Sciences 6(11): 466-473.

[8] Esfahlan, A. J., Esfahlan, R. J., Jamei, R., Esfahlan, A. J. (2012): Morphology and physicochemical properties of 40 genotypes of almond (Amygdalus communis L.) fruits. European Journal of Experimental Biology 2(6): 2456-2464.

[9] Evanno, G., Regnaut, S., Goudet, J. (2005): Detecting the number of clusters of individuals using the software STRUCTURE: a simulation study. - Molecular Ecology 14(8): 26112620.

[10] Gouta, H., Ksia, E., Zoghlami, N., Zarrouk, M., Mliki, A. (2008): Genetic diversity and phylogenetic relationships among Tunisian almond cultivars revealed by RAPD markers. - The Journal of Horticultural Science and Biotechnology 83(6): 707-712. 
[11] Grasselly, C. (1976): Origine et evolution de l'amandier cultive. - Options Méditerraneeneene 32: 45-49.

[12] Gupta, P. K., Varshney, R. K. (2000): The development and use of microsatellite markers for genetic analysis and plant breeding with emphasis on bread wheat. - Euphytica 113(3): 163-185.

[13] Halász, J., Kodad, O., Galiba, G. M., Skola, I., Ercisli, S., Ledbetter, C. A., Hegedüs, A. (2019): Genetic variability is preserved among strongly differentiated and geographically diverse almond germplasm: an assessment by simple sequence repeat markers. - Tree Genetics \& Genomes 15(1): 1-12.

[14] i Martí, A. F., i Forcada, C. F., Kamali, K., Rubio-Cabetas, M. J., Wirthensohn, M., i Company, R. S. (2015): Molecular analyses of evolution and population structure in a worldwide almond [Prunus dulcis (Mill.) D.A. Webb syn. P. amygdalus Batsch] pool assessed by microsatellite markers. - Genetic Resources and Crop Evolution 62(2): 205219.

[15] Janick, J. (1990): Plant Breeding Reviews, Volume 8. - John Wiley \& Sons, Inc.

[16] Jordano, P., Godoy, J. A. (2000): RAPD variation and population genetic structure in Prunus mahaleb (Rosaceae), an animal-dispersed tree. - Molecular Ecology 9: 1293-1305.

[17] Kester, D. E., Gradziel, T. M. (1996): Almonds (Prunus). - In: Moore, J. N, Janick, J. (ed.) Fruit Breeding. Wiley and Sons, New York.

[18] Khan, A., Sovero, V., Gemenet, D. (2016): Genome-assisted breeding for drought resistance. - Current genomics 17(4): 330-342.

[19] Kodad, O., Lebrigui, L., El-Amrani, L., i Company, R. S. (2014): Physical fruit traits in Moroccan almond seedlings: Quality aspects and post-harvest uses. - International Journal of Fruit Science 15(1): 36-53.

[20] Kumar, D., Ahmed, N. (2015): Morphological and pomological evaluation of almond (Prunus dulcis) cultivars under North West Himalayan region of India. - International Journal of Horticulture 5(15): 1-6.

[21] Ladizinsky, G. (1999): On the origin of almond. - Genetic Resources and Crop Evolution 46(2): 143-147.

[22] Martins, M., Tenreiro, R., Oliveira, M. M. (2003): Genetic relatedness of Portuguese almond cultivars assessed by RAPD and ISSR markers. - Plant cell reports 22(1): 71-78.

[23] Pinar, H., Ercisli, S., Unlu, M., Bircan, M., Uzun, A., Keles, D., Baysal, F., Atli, H. S., Yilmaz, K. U. (2015): Determination of genetic diversity among some almond accessions. - Genetika 47(1): 13-22.

[24] Sakar, E. H., El Yamani, M., Rharrabti, Y. (2019): Geometrical traits in almond fruit as affected by genotypic and environmental variations in Northern Morocco. - ErwerbsObstbau 61(2): 103-112.

[25] Saleh, S., Ehsan, N., Mohamed, S., Mohamed, T. (2018): Molecular genetic variability of some deciduous fruit rootstocks in Egypt. - Journal of Scientific Research in Science 35(1): 95-111.

[26] Sánchez-Pérez, R., Pavan, S., Mazzeo, R., Moldovan, C., Cigliano, R. A., Del Cueto, J., Ricciardi, F., Lotti, C., Ricciardi, L., Dicenta, F., López-Marqués, R. L., Møller, B. L. (2019): Mutation of a bHLH transcription factor allowed almond domestication. - Science 364(6445): 1095-1098.

[27] Sarhan, S., Hamed, F., Lawand, S., Al-Youssef, W. (2015): Relationships among Peach, almond, and related species as detected by SSR/ ISSR markers. - International Journal of ChemTech Research 8(1): 82-88.

[28] Sharma, D., Kaur, R., Kumar, K., Bhardwaj, S. (2012): Genetic diversity among selected genotypes of almond Prunus dulcis Miller D.A. Webb assessed by random amplified polymorphic DNA (RAPD) markers. - African Journal of Biotechnology 11(83): 1487714883. 
[29] Sharma, P., Sharma, R. (2018): DNA fingerprinting of peach (Prunus persica) germplasm in accessing genetic variation using arbitrary oligonucleotide markers system. - Indian Journal of Biotechnology 17(3): 484-491.

[30] Shiran, B., Amirbakhtiar, N., Kiani, S., Mohammadi, S. H., Sayed-Tabatabaei, B. E., Moradi, H. (2007): Molecular characterization and genetic relationship among almond cultivars assessed by RAPD and SSR markers. - Scientia Horticulturae 111(3): 280-292.

[31] Sorkheh, K., Shiran, B., Gradziel, T. M., Epperson, B. K., Martínez-Gómez, P., Asadi, E. (2007): Amplified fragment length polymorphism as a tool for molecular characterization of almond germplasm: genetic diversity among cultivated genotypes and related wild species of almond, and its relationships with agronomic traits. - Euphytica 156(3): 327344.

[32] Sorkheh, K., Shiran, B., Kiani, S., Amirbakhtiar, N., Mousavi, S., Rouhi, V., Mohammady, D. S., Gradziel, T. M., Malysheva-Otto, L. V., Martínez-Gómez, P. (2009): Discriminating ability of molecular markers and morphological characterization in the establishment of genetic relationships in cultivated genotypes of almond and related wild species. - Journal of Forestry Research 20(3): 183-194.

[33] Tahir, N. A., Hama Karim, H. F. (2011): Determination of genetic relationship among some varieties of chickpea (Cicer arietinum L) in Sulaimani by RAPD and ISSR markers. Jordan Journal of Biological Sciences 4(4): 77-86.

[34] Tahir, N. A., Omer, D. A., Lateef, D. A., Ahmad, S. H., Salih, S. H., Hiwakhal, L. (2019): Diversity and population structure analysis of faba bean (Vicia faba L.) accessions using SSR markers. - Journal of Agricultural Science and Technology 21(2): 463-474.

[35] Terzopoulos, P. J., Bebeli, P. J. (2008): Genetic diversity analysis of Mediterranean faba bean (Vicia faba L.) with ISSR markers. - Field Crops Research 108(1): 39-44.

[36] Tian, Y., Xing, C., Cao, Y., Wang, C., Guan, F., Li, R., Meng, F. (2015): Evaluation of genetic diversity on Prunus mira Koehne by using ISSR and RAPD markers. Biotechnology, Biotechnological Equipment 29(6): 1053-1061.

[37] United States Department of Agriculture National Agricultural Statistics Service USDA (2018): California Almond Forecast. -

https://www.nass.usda.gov/Statistics_by_State/California/Publications/Specialty_and_Ot her_Releases/Almond/Forecast/201805almpd.pdf.

[38] Wang, Z., Kang, M., Liu, H., Gao, J., Zhang, Z., Li, Y., Wu, R., Pang, X. (2014): Highlevel genetic diversity and complex population structure of Siberian apricot (Prunus sibirica L.) in China as revealed by nuclear SSR markers. - PLoS One 9(2): e87381.

[39] Woolley, F. M., Collins, G. G., Sedgley, M. (2000): Application of DNA fingerprinting for the classification of selected almond [Prunus dulcis (Mill.) D. A. Webb] cultivars. Australian Journal of Experimental Agriculture 40(7): 995-1001.

[40] Xu, Y., Ma, R. C., Xie, H., Liu, J. T., Cao, M. Q. (2004): Development of SSR markers for the phylogenetic analysis of almond trees from China and the Mediterranean region. Genome 47(6): 1091-1104.

[41] Zeinalabedini, M., Majourhat, K., Khayam-Nekoui, M., Grigorian, V., Torchi, M., Dicenta, F., Martínez-Gómez, P. (2008): Comparison of the use of morphological, protein and DNA markers in the genetic characterization of Iranian wild Prunus species. - Scientia Horticulturae 116(1): 80-88.

[42] Zhu, Y. (2014): Almond (Prunus dulcis (Mill.) D.A. Webb) fatty acids and tocopherols under different conditions. - PhD Thesis, School of Agriculture, Food and Wine. University of Adelaide, Australia. 